\title{
A ATUAÇÃO DA MÍDIA REFLETIDA NAS DECISÕES DO TRIBUNAL DO JÚRI
}

Carol Cristina da Silva Ruiz', Eduardo Buzetti Eustachio Bezerro²

Universidade do Oeste Paulista - UNOESTE, Curso de Direito, Presidente Prudente/SP. E-mail: carolcruiz@hotmail.com

\section{RESUMO}

O presente estudo pondera o conflito entre duas garantias protegidas pela Constituição Federal de 1988: a liberdade de expressão e a liberdade de informar em confronto com o princípio da dignidade da pessoa humana. Ao exercer a liberdade de expressão expondo fatos criminosos com a intenção de comover a sociedade e garantir níveis de audiências elevados compromete as decisões do conselho de sentença, cuja competência é julgar os crimes dolosos contra a vida, pois os julgadores são pessoas da sociedade, leigas do sistema judiciário e passíveis de serem influenciados. Considerando que a divulgação demasiada dos envolvidos em crimes cruéis revoltará a sociedade, motivando o pré-julgamento dos suspeitos, antes mesmo do devido processo, abalando os vereditos.

Palavra - chave: Garantias. Dignidade Humana. Mídia. Influência. Jurados.

\section{MEDIA ACTIVITY REFLECTED IN THE JURY IS DECISIONS}

\section{ABSTRACT}

The present study considers the conflict between two rights protected for the federal Constitution of 1988: the freedom of speech and freedom to inform in against principle human dignity. To exercise the freedom of speech exposing criminal acts with intention to cause commotion in the society and to get high levels of audience commits the decision of council whose responsibility is to judge the crimes against life, because the jury are people in society, lay of the judiciary system and can be influenced. Considering the excessive disclosure involved in cruel crimes cause social revolt, motivating the pre-trial of the suspects, even before the judgment, and disturbing the verdicts.

Keywords: Warranty. Human Dignity. Media. Influenced. Jurys. 


\section{INTRODUÇÃO}

Nos tempos de hoje, em constante desenvolvimento tecnológico, as pessoas sentem a necessidade da informação. São muitas maneiras de obter e transmitir uma notícia, tornando-se ágil saber o que acontece mundo a fora. Os meios de comunicação estão mais presentes na vida das pessoas. Utilizados na busca de diversas informações, que vão desde os meios tradicionais, como um jornal impresso ou um programa de televisão até um pequeno smartphone com acesso a internet.

A comunicação em massa é importante para a democracia de um país e para o desenvolvimento da personalidade do ser humano, mas a distorção de algumas notícias, principalmente nos programas sensacionalistas, cujo objetivo é comover seu público, atraindo níveis de audiências, afetará a vida dos envolvidos, principalmente os acusados de crimes dolosos contra a vida, na qual sua competência para julgar é a própria sociedade.

Diante disso, o objetivo é demonstrar que a liberdade de imprensa não é absoluta, pois o excesso de informações causará um desequilíbrio na vida do indivíduo, violando os princípios básicos para uma vida digna; e explicará o procedimento do tribunal do júri e o porquê o excesso de informação influenciará nas decisões desse julgamento.

O estudo será de importância acadêmica e cientifica, e despertará interesse de discussões relacionadas aos assuntos presentes na mídia, com grande relevância.

\section{METODOLOGIA}

A pesquisa será desenvolvida a partir de análise legislativa, levantamento bibliográfico e artigos científicos. O tema será discutido levando em consideração as características gerais do método hipotético-dedutivo, cujos resultados serão discutidos, permeado por uma reflexão crítica da problemática.

\section{A LIBERDADE DE EXPRESSÃO COMO UMA GARANTIA RELATIVA}

O Brasil, como um Estado Democrático de Direitos, possibilita a qualquer cidadão o direito de informar e ser informado. Essa liberdade é tipificada no artigo 5o inciso IX, da Constituição Federal, o qual dispõe sobre a liberdade da comunicação, independentemente de censura ou licença. A Constituição no mesmo sentido possui um capítulo próprio sobre a liberdade de expressão, cujo titulo é "comunicação social", e o texto expressa:

Art. 220. A manifestação do pensamento, a criação, a expressão e a informação, sob qualquer forma, processo ou veiculo não sofrerão qualquer restrição, observando o disposto nesta Constituição.

Ao dizer "observando o disposto nesta Constituição", o legislador demonstra o porquê não se pode dizer que é uma garantia absoluta. Prosseguindo com a leitura do artigo, o § $1^{\circ}$ enuncia que a liberdade de expressão se limitará quando colidir com o princípio da dignidade da pessoa humana, ferindo o direito à vida, à intimidade, à honra e à privacidade; o artigo 221, inciso IV protege também os valores éticos e sociais da pessoa e da família. Por isso, não havendo uma barreira, gerará um desequilíbrio para a sociedade e principalmente para a vida do indivíduo.

Sendo assim, a menção "não sofrerão qualquer restrição" não é ilimitada, e havendo excessos, responderá tanto no âmbito penal quanto no civil, indenizando pelo dano material ou moral que houver causado.

\section{O FUNCIONAMENTO DO TRIBUNAL DO JÚRI NO BRASIL}


Conforme os ensinamentos de Tasse e Gomes (2012, p. 13), a instituição do júri iniciou-se no século XVIII com a intenção de julgar os crimes de abuso da liberdade de imprensa. Ao longo do tempo ocorreram mudanças no conceito, mas em 05 de outubro de 1988, a Constituição Federal incluiu o tribunal do júri dentro "Dos Direitos e Garantias Individuais", artigo $5^{\circ}$ inciso XXXVIII, com a finalidade de os acusados de crimes dolosos contra a vida serem julgados por seus pares, ou seja, as pessoas leigas do sistema processual. A lei de 11.689/2008 reestruturou os artigos 406 a 497 do Código de Processo Penal, considerando o Júri um rito especial.

Goza de quatro princípios previstos no artigo 5o XXXVIII, sendo eles: a) Plenitude de defesa: equivale a abrangência da defesa técnica, ou seja, a defesa regular não é aceita e o defensor deverá se valer da mais perfeita defesa para a absolvição do réu. Tasse e Gomes (2012, p. 34) ensinam que "A defesa plena não se esgota apenas nos argumentos jurídicos, e sim, também, em recursos psicológicos emocionais, em tese culturais etc."; b) sigilo das votações: é vedado aos jurados a comunicação uns com os outros, evitando assim, uma possível influência na hora da votação. A opinião dos jurados deve ser resguardada; c) soberania dos vereditos: apenas o júri popular é competente para decidir, impedindo o juiz modificar as decisões. Havendo erros ou recursos, o caso continuará sendo julgado por um novo conselho de sentença; d) competência mínima para julgar os crimes dolosos contra a vida: a atribuição é para julgar os crimes tanto na forma tentada ou consumada, previstos pelos artigos 121 a 126 do Código Penal. Nucci, (2015, p. 1) explica que "É viável que os jurados decidam condenar ou absolver o autor de um estupro ou de ou roubo, por exemplo, bastando que o delito seja conexo ao crime doloso contra a vida.". Os crimes culposos não serão de competência do júri, mas sim do juiz singular.

Embora haja doutrinadores que acreditam ser um procedimento trifásico, o processo é dividido em duas fases, das quais veremos a seguir:

A primeira fase, conhecida como sumário de culpa, é prevista nos artigos 406 a 421 do código de processo penal. Nos ensinamento de Tasse e Gomes (2012, p. 44), o Ministério Público oferecerá a denúncia ou queixa e o juiz rejeitará ou acatará o recebimento. Se a denuncia for recebida, o juiz citará o acusado para oferecer a preliminar de defesa no prazo de dez dias, independentemente do acusado preso ou em liberdade. Após a citação e a apresentação da defesa, inicia-se a audiência de instrução e julgamento, ouvindo as partes e as testemunhas.

Encerrado a audiência, o juiz fundamentando sua decisão, proferirá se é admissível o julgamento pelo tribunal do júri.

Após o trânsito em julgado da pronúncia do juiz, inicia-se a segunda fase preparando o plenário para julgamento. Intima-se o Ministério Público e o defensor para arrolar as testemunhas e a produzir provas a serem apresentadas em plenário.

A composição da sessão é de um juiz presidente, cuja função é controlar a sessão, sortear os jurados e sanar quaisquer dúvidas destes; e 25 jurados, leigos do sistema processual, dos quais serão sorteadas sete pessoas aptas para constituir o Conselho de Sentença. Para instalar os trabalhos, é necessário comparecer o quorum mínimo de 15 jurados.

Qualquer cidadão, de todas as classes sociais, brasileiro nato ou naturalizado, maior de 18 anos, capaz, alfabetizado e idôneo, poderá participar do rol de jurados. Conforme salienta Nucci (2015), a função de jurado é obrigatória, tipificado no artigo 436 do código de processo penal, exceto para as pessoas descritas no artigo 437, e a recusa injustificada constituirá crime de desobediência, acarretando multa de um a dez salários mínimos computados conforme a renda do cidadão; a recusa por motivo de crença religiosa ou conviçcão filosófica importará a prestação de serviço alternativo sob a pena da perda dos direitos políticos, conforme dispõe o artigo 438.

Ao serem sorteados, os jurados farão o juramento conforme descreve Capez (2014, p. 215) 
Composto o Conselho de Sentença, os jurados escolhidos prestarão compromisso, em pé, diante da seguinte exortação do juiz presidente: "Em nome da lei, concito-vos a examinar esta causa com imparcialidade e a proferir a vossa decisão, de acordo com a vossa consciência e os ditames da justiça"; chamados um a um, pelo nome, deverão responder: "Assim o prometo". A partir do juramento, passa a valer o dever de incomunicabilidade, não podendo os jurados comunicar-se entre si ou com outrem, nem manifestar sua opinião sobre o processo, sob pena de exclusão do Conselho e multa, na forma do $\S 20$ do art. 436 do Código.

Após a escolha dos jurados e o juramento destes, iniciam-se os debates entre promotor e defensor, com direito a réplica e a tréplica, convencendo os jurados à escolha entre a absolvição ou a condenação. A decisão é pela maioria dos votos, ou seja, se houver quatro votos iguais, o julgamento será finalizado.

\section{A MÍDIA SENSACIONALISTA E SEU REFLEXO NAS DECISÕES DO CONSELHO DE SENTENÇA.}

Conforme abordado, a liberdade de expressão e a liberdade de informar são importantes garantias constitucionais para a democracia de um país e para a vida do ser humano. Segundo Oliveira, (2013, p.1691), "só é possível cogitar de opinião pública livre onde existe liberdade de informação jornalística. Por isso, entende-se que esta, mais do que um direito, é uma garantia institucional da democracia".

Todavia, a distorção de algumas notícias, principalmente aquelas voltadas para o âmbito penal e o excesso de exposição dos envolvidos, colidirá com os bens mais importantes para o ser humano, seja a intimidade, a privacidade, a vida e principalmente sua liberdade. Nessa linha de pensamento, Schreiber, em sua obra, cita Machado de Assis (2013, p. 09), "O maior pecado, depois do pecado, é a publicação do pecado".

A exibição dos fatos em programas sensacionalistas, cujo objetivo é comover seu público e garantir níveis de audiência, como exemplo o programa "Brasil Urgente" apresentado por José Luiz Datena, nos faz acreditar e pré-condenar os envolvidos da notícia. À vista disso, a presunção de inocência antes do trânsito em julgado é em vão, pois ao divulgar com ênfase, criticando e expondo suas opiniões momentâneas, sem base jurídica, levará o telespectador a crer fielmente na notícia, gerando possíveis consequências para o sujeito em foco.

A dignidade humana e a presunção de inocência não são os únicos princípios a serem confrontados por esses programas. O procedimento do tribunal do júri também é afetado. Ora, ao finalizar a primeira fase do júri, o juiz ao pronunciar sua decisão não poderá aprofundar sua fundamentação, pois poderá influenciar as decisões dos jurados; aos jurados, respeitando o princípio do sigilo às votações, não poderão comunicar-se uns com os outros, para não intervir nas votações dos demais; e ainda, se o réu estiver preso, em regra, deverá permanecer no plenário sem algemas, também para não induzir os jurados. Mas e a mídia? Sua liberdade de informar não poderia influenciar os jurados?

Além de induzir os jurados, induzirá uma sociedade inteira, podendo colocar em risco a vida do suspeito, pois ao relatar um crime cruel, gerará o clamor público no ritmo de fazer a justiça com as próprias mãos.

Querem noticiar primeiro que os demais programas, aumentando seus níveis de audiência, sem atentar-se que os envolvidos poderão ser perseguidos, humilhados, massacrados, desrespeitando os princípios dos indivíduos e, ainda influenciando as decisões que os jurados deverão tomar, votando aos moldes da mídia. Mesmo o legislador tomando os cuidados necessários, a mídia é capaz de influenciar as decisões, uma vez que o reflexo midiático criará uma pressão na vida dos jurados e a intimidação feita pela imprensa poderá se voltar contra eles. 


\section{CONCLUSÃO}

Para exercer a democracia plena, é necessário que haja a liberdade de expressão e de comunicação vedando a sua censura, mas não havendo um limite, ocorrerão consequências imensuráveis na vida da vítima, do acusado e de sua família.

A relevância dos assuntos criminais nos faz acreditar e pré-condenar os envolvidos da notícia. Com isso, percebemos que os crimes com competência do júri popular, o acusado poderá ser prejudicado ou beneficiado, dependendo da sua imagem retratada na imprensa. Podemos buscar os instrumentos e recursos de defesa e acusação previstos em lei, contudo, seria possível a total eficácia, visto a imposição da mídia?

Nota-se que a presunção de inocência do sujeito é violada, pois o excesso de informação do caso retratado na imprensa influenciará as decisões dos jurados leigos, visto que poderão estar com o veredito de condenação concluído, cabendo ao promotor de justiça uma acusação mais complexa ou ao defensor público maior esforço para driblar o sensacionalismo midiático, evitando a condenação de um inocente ou absolvição de um culpado, vítima da manipulação da imprensa.

Destarte, a proporcionalidade das garantias vistas deve ser imprescindível, mantendo as notícias de modo informativo imparcial, evitando influências e erros com danos imensuráveis para a vida das pessoas.

\section{REFERÊNCIAS}

Capez, F. Processo Penal Simplificado. 20e ed. São Paulo: Saraiva, 2014. Disponível em:

$<$ https://integrada.minhabiblioteca.com.br/\#/books/9788502164932/cfi/0>. Acesso em 03 agos. 2016.

Moraes, A. Direito Constitucional. 29 ed. São Paulo: Atlas, 2013.

LIRA, R. S. Mídia Sensacionalista: o segredo de Justiça. Rio de Janeiro: Forense, 2014. Disponível em: < https://integrada.minhabiblioteca.com.br/\#/books/978-85-309-5930-2/cfi/6/2>. Acesso em 03 agos. 2016.

NUCCI, G. Tribunal do Júri. 6o ed. Rio de Janeiro:Forense, 2015. Disponível em: <https://integrada.minhabiblioteca.com.br/\#/books/978-85-309-6292-0/cfi/6/2>. Acesso em 05 agos. 2016.

OLIVEIRA, J.E. Constituição Federal: anotada e comentada. Rio de Jaineiro: Forense, 2013. Disponível em: < https://integrada.minhabiblioteca.com.br/\#/books/978-85-309-4667-

8/cfi/0!/4/4@0.00:0.00>. Acesso em 02 agos. 2016.

SCHREIBER, A. Direito e mídia. São Paulo: Atlas, 2013. Disponível em:

<https://integrada.minhabiblioteca.com.br/\#/books/9788522477494/cfi/0!/4/2@100:0.00>. Acesso em 03 agos. 2016.

TASSE, A.E; GOMES, L.F. Processo Penal IV Júri. São Paulo: Saraiva, 2012. Disponível em: < https://integrada.minhabiblioteca.com.br/\#/books/9788502171244/cfi/0>. Acesso em 03 agos. 2016.

VADE MECUM Edição especial. 3o ed. São Paulo: revista dos Tribunais, 2015. 